\title{
Fate of insulin in the retina: an autoradiographic study
}

\author{
C. R. H. JAMES AND E. COTLIER \\ From the Department of Ophthalmology and Visual Science, Yale School of Medicine, New Haven, \\ Connecticut, USA
}

SUMMARY A system for whole-blood perfusion of the bovine eye through the cilioretinal artery was developed and the distribution and binding of ${ }^{125} \mathrm{I}$-labelled insulin and human growth hormone (HGH) were studied autoradiographically. Sodium fluorescein was used as a tracer to monitor blood retinal barrier integrity, and electron microscopy was used to determine structural preservation after perfusion fixation. With this system, barrier integrity and structural perservation of both the neural retina and the retinal blood vessels were regularly obtained, with perfusion periods of as long as 5 hours. By quantitative light microscopy autoradiography, insulin binding sites were identified on the endothelial cells of retinal capillaries after perfusion with blood containing ${ }^{125} \mathrm{I}$-insulin. ${ }^{125} \mathrm{I}$-insulin binding was competitively inhibited by the addition of unlabelled insulin to the perfusing blood. By contrast the low level of binding of $\mathrm{HGH}$ to retinal capillaries was nonspecific. Electron microscopy autoradiography revealed ${ }^{125}$ I-insulin autoradiographic grains lying over the endothelial cell wall, over pinocytotic vesicles, and over the cytoplasm of both endothelial cells and pericytes. This suggests that, after binding to the cell surface, some insulin passes into the cell cytoplasm. However, neither ${ }^{125} \mathrm{I}$ nor ${ }^{125} \mathrm{I}-\mathrm{HGH}$ penetrated as far as the retina in the periods studied.

Although blindness secondary to microvascular disease is a major complication of diabetes, insulin's physiological role in the eye is unknown beyond the fact that it does not affect glucose uptake. ${ }^{1}$ However, it is known that insulin binds specifically to brain capillaries and umbilical vessels. ${ }^{23}$ It has also been suggested that insulin stimulates vesicular transport across muscle capillary walls and that this effect is reduced by diabetes. ${ }^{4}$

Recently there have been preliminary reports of specific insulin binding sites in isolated retinal capillary preparations at $22^{\circ} \mathrm{C}^{5}$ and in cultured retinal pericytes at $4^{\circ} \mathrm{C} .^{6}$ The purpose of this study was to assess the characteristics of insulin binding in retinal capillaries in an intact eye perfused with blood at $37^{\circ} \mathrm{C}$ and to assess whether binding influences distribution in the retina.

The fact that human growth hormone (HGH) is implicated in diabetic retinopathy is well established, ${ }^{7 \rightarrow}$ but the mechanism is not understood. Capillary binding sites for $\mathrm{HGH}$ were not found in the brain, ${ }^{2}$ but in view of the differing effects diabetes has on the 2 circulations the retinal capillary binding behaviour of $\mathrm{HGH}$ was also studied.

Correspondence to Dr C. James, Moorfields Eye Hospital, City Road, London EC1V 2PD.
The bovine eye was chosen because insulin binding sites had already been found in an isolated bovine

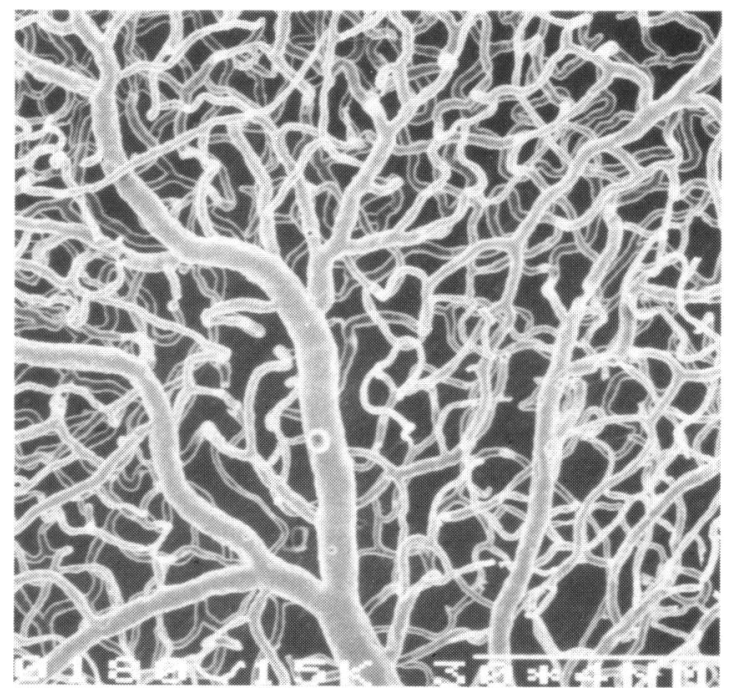

Fig. 1 Scanning electron microscopic appearances of an acrylic cast of the inner retinal microcirculation of a bovine eye. Note the superficial and deep capillary layers. (In collaboration with $\mathrm{Dr} T$. Sherk). 


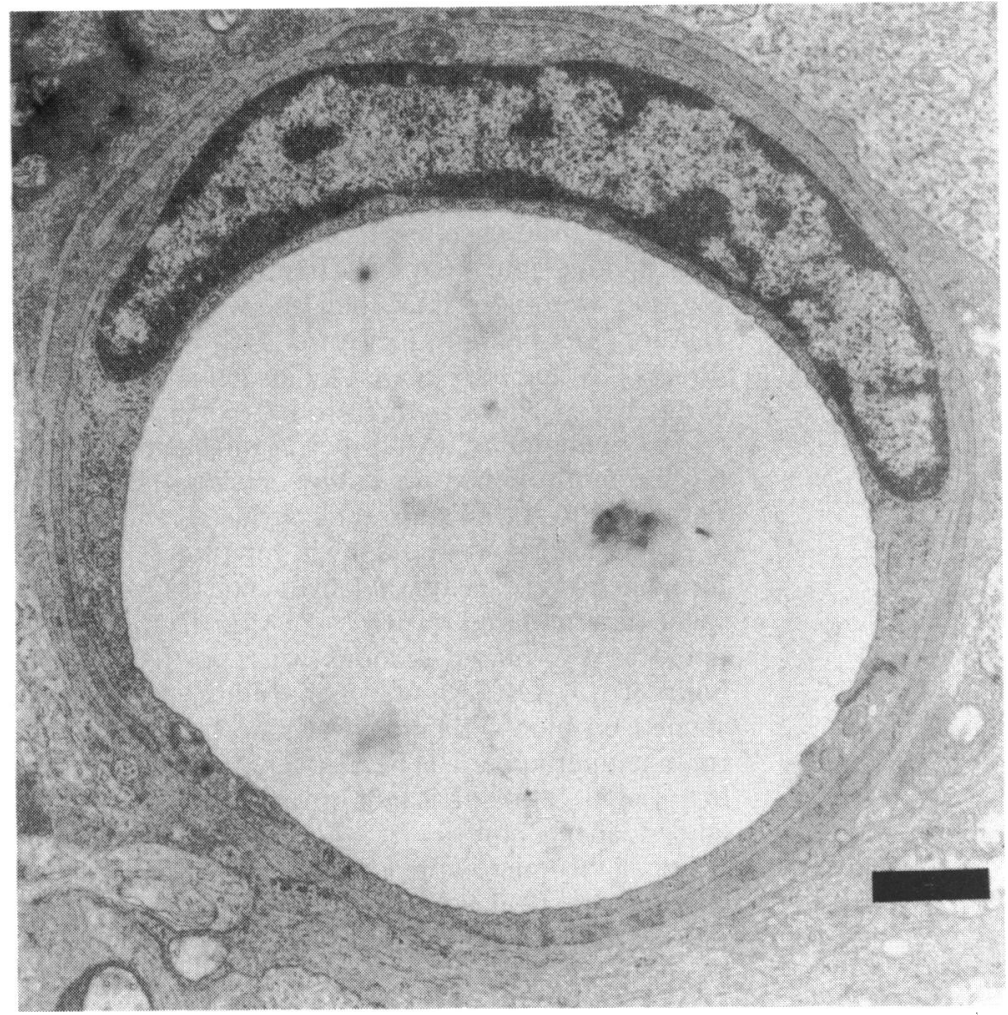

Fig. 2 Electron microscopic appearances of a bovine retinal capillary following perfusion fixation. $($ Bar $=1 \mu \mathrm{m})$.

retinal microvessel preparation. ${ }^{5}$ Furthermore, the cow, like man, has a holangiotic fundus, ${ }^{11}$ with the inner half of the retina receiving its blood supply from a dense capillary network (Fig. 1). One artery, the cilioretinal artery, supplies the whole ocular vascular bed,,$^{12}$ and it has been previously shown that it is possible to cannulate this artery and perfuse the eye with blood for periods of several hours while maintaining normal structure and function. ${ }^{13} 14$

\section{Materials and methods}

Perfusion. Bovine eyes were perfused with blood immediately after death by a modification of the technique originally described by Seaman et al. ${ }^{13}$ Freshly obtained bovine blood was collected in the slaughter-house in a siliconised bottle containing 3000 $U S P$ units of heparin. Air was then pumped through a gas dispersion rod until the blood gas levels rose to within arterial limits $\left(\mathrm{Po}_{2} 90-100 \mathrm{mmHg}, \mathrm{PCO}_{2} 25-35\right.$ $\mathrm{mmHg}$, pH 7.35-7.45).

This 'arterialised' blood was then drawn into a syringe and connected to siliconised tubing that culminated in a fine polyethylene cannula narrow enough to enter the cilioretinal artery. A freshly enucleated eye with a long section of optic nerve was obtained, and with the aid of a portable operating microscope (Zeiss OP-MIX) the cannula was rapidly inserted into the cilioretinal artery and sutured in place. Warmed $\left(37^{\circ} \mathrm{C}\right)$ heparinised normal saline was gently flushed through the eye to expel native blood from the circulation, and this was immediately followed by blood at a rate of $1 \mathrm{ml} / \mathrm{min}$ at a pressure of 70-80 $\mathrm{mmHg}$ from a portable precalibrated syringe pump (Autosyringe Model 5B). The eye could then be placed in an apparatus containing warm water to maintain both the eye and incoming blood at $37^{\circ} \mathrm{C}$ for transport to the laboratory. $1 \mathrm{ml} / \mathrm{min}$ was the rate we found blood spontaneously flowed through the eye when a blood reservoir was suspended above the eye to produce a hydrostatic pressure of $70 \mathrm{mmHg}$ and was also the rate used by Seaman et al. ${ }^{13}$

The uniformity of blood flow and the patency of the blood retinal barrier were checked in each experiment by injecting $2-5 \mathrm{mg}$ of sodium fluorescein into the perfusing blood. The ensuing fluorescein angiogram could be monitored either with a direct ophthalmoscope or on film. After fixation the retina was also examined under ultraviolet light for the presence of extravasated fluorescein. The patency of the bloodretinal barrier was regularly maintained for periods of more than 5 hours, and excellent structural preservation was evident on electron microscopy of eyes perfused for this period (Fig. 2). 


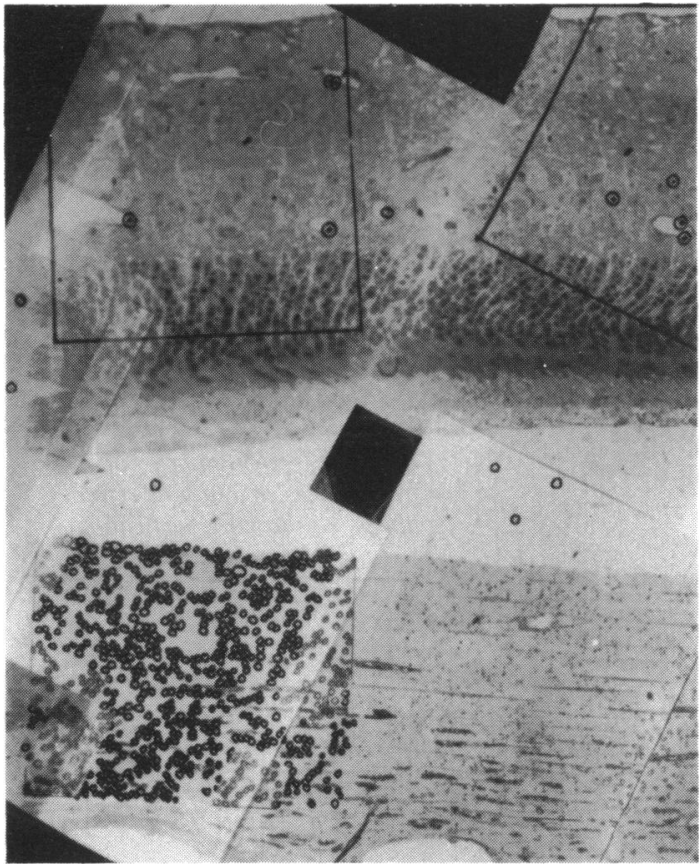

Fig. 3 Composite photomicrograph of bovine retina after perfusion with ${ }^{125}$ I-insulin followed by perfusion fixation. Autoradiographic grains have been circled, and enclosed in grids for regional grain density estimation (see text). Note high choroidal and tapetal grain density, low retinal and background density, and grains over capillary walls. $(\times 215)$.
Iodination of hormones. Insulin and growth hormone were iodinated at room temperature by the chloramine-T technique. ${ }^{15}$ Free ${ }^{125}$ I was separated from labelled hormone by gel filtration (Sephadex G25). Radioactivity precipitable in $10 \%$ trichloracetic acid (TCA), and binding by antibody were then determined ${ }^{16}$ before each batch of radiolabelled hormone was divided into identical aliquots and frozen. No aliquots were used later than one week after manufacture. The final product was $>94 \%$ precipitable in $10 \%$ TCA and $90 \%$ bound by insulin antibody, and ranged in specific activity from 100 to $150 \mu \mathrm{Ci} / \mu \mathrm{g}$.

Autoradiography. After perfusion each eye was flushed gently with normal saline to clear the circulation of blood and then fixed by perfusion and topical application of a fresh aldehyde mixture (2\% paraformaldehyde, $2 \%$ glutaraldehyde, and $0 \cdot 1 \mathrm{M}$ sodium cacodylate buffered to $\mathrm{pH} 7 \cdot 4$ ). After fixation for 2 hours at $4^{\circ} \mathrm{C}$ retinal sections were postfixed for 2 hours in $1 \% \mathrm{OsO}_{4}$ in Veronal-acetate, rinsed, and stained en bloc with uranyl acetate for 3 hours at room temperature. The blocks were then dehydrated in graded ethanols and propylene oxide and embedded in Epon.

For light microscopy autoradiography sections were cut at a thickness of $0.5 \mu \mathrm{m}$, coated with Ilford $\mathrm{K} 5$ emulsion, and developed after 30 days at $4^{\circ} \mathrm{C}$. For electron microscopy autoradiography the flat substrate technique of Salpeter and Bachman ${ }^{17}{ }^{18}$ was followed, with Ilford L-4 emulsion. Sections were $60-90 \mathrm{~nm}$ thick and the emulsion layer was about $0 \cdot 1$

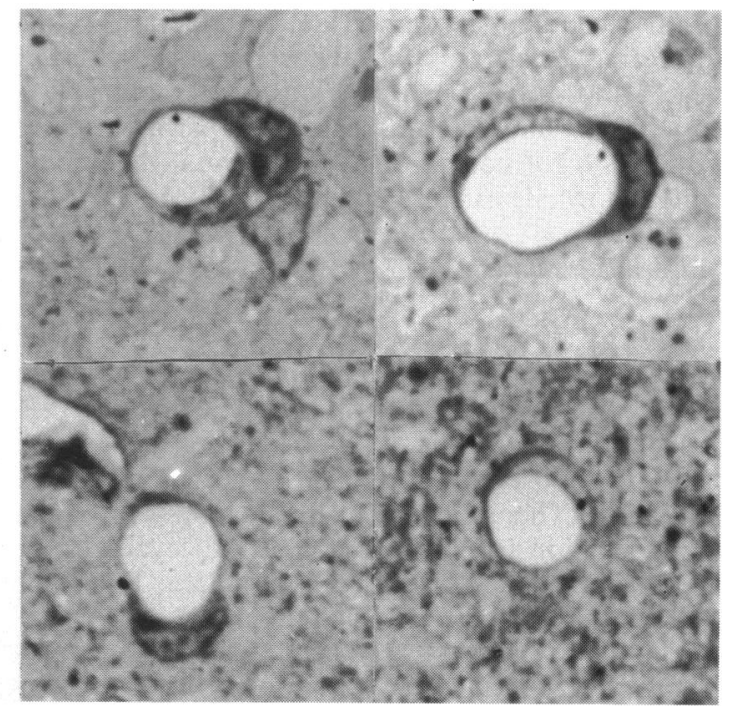

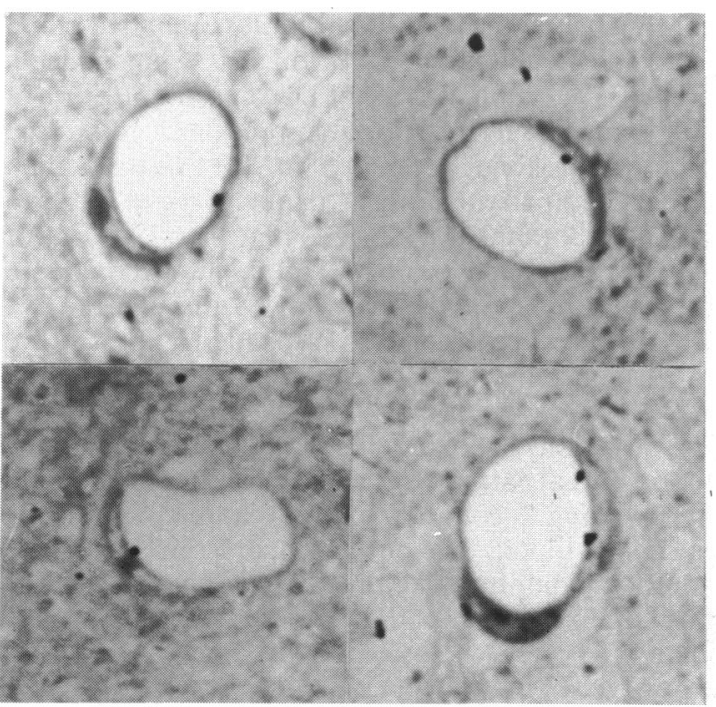

Fig. 4 Light microscopic appearances of capillary wall associated ${ }^{125}$ I-insulin autoradiographic grains. $(\times 1650)$. (Left)
Grains lying crisply over the cytoplasm/lumen interface. These represented the majority of the capillary wall associated grains, and were counted for quantification (see text). (Right) Grains lying adjacent to the cytoplasm/lumen interface; either luminal (above) or cytoplasmic (below). These were not used for quantification. 
$\mathrm{nm}$ thick. After an exposure time of 60 days the preparations were developed with Microdol-X for 3 min at $20^{\circ} \mathrm{C}$. After removal of the overlying collodion the sections were stained with uranyl acetate and lead citrate and examined in a Phillips 301 electron microscope.

\section{GRAIN COUNTING}

Distribution. Grain densities were measured at $\times 1500$ magnification from photographs taken with a Zeiss photo-microscope (Fig. 3).

Light microscopy quantitative binding. Slides were directly examined under uniform illumination conditions by one observer (C.J.) at a magnification of $\times 1500$, and capillary internal diameters were measured with an ocular micrometer (AO 1406A).

Criteria to be met by a retinal capillary profile before counting were. (1) presence of one endothelial nucleus: \pm one pericyte nucleus; (2) empty lumen; (3) 4-14 $\mu \mathrm{m}$ mean diameter; (4) good structural preservation.

To be counted as a capillary wall autoradiographic grain the grain had to be sharply on the interface between cell cytoplasm and lumen. All other grains were ignored (Fig. 4). Sections were prepared from each of the 4 main areas: next to the 'area striata' (or perimacula), equatorial, peripheral-tapetal, and peripheral non-tapetal, in each experimental retina. Several $0.5 \mu \mathrm{m}$ tissue sections were then prepared for autoradiography from each area. Each section, containing 20 or more suitable vessel profiles, was counted as a separate unit. The total number of grains lying on the vessel wall/lumen interface in suitable capillaries in each section was counted according to the criteria above, and the internal circumference for each counted capillary was calculated after measuring its mean internal diameter with the ocular micrometer. The total number of capillary wall grains for each section was then divided by the product of the total internal circumference of the vessels counted and the section thickness $(0.5 \mu \mathrm{m})$. In this way a value for the section grain density was obtained:

$\begin{aligned} & \begin{array}{l}\text { Section grain density } \\ \text { (expressed as grains per } \\ 100 \mu \mathrm{m}^{2} \text { of capillary wall } \\ \text { internal surface area) }\end{array} \\ & \begin{array}{l}\text { Total capillary internal } \\ \text { circumference } \times 0.5 \mu \mathrm{m}\end{array}\end{aligned}, \times 100$

The total number of sections counted for each experimental eye $=n$ for that experiment, and the mean grain density \pm the standard deviation for each experimental eye was calculated from the sum of the section grain densities. Slides were coded to reduce observer bias. For the electron microscopy studies the distance from the grain centre to the plasma membrane was measured directly on photographic prints at a final magnification of $\times \mathbf{4 0 5 0 0}$. All $p$ values of statistical significance were calculated by Student's $t$ test.

\section{Results}

Distribution (see Fig. 3)

Perfusion with either ${ }^{125}$ I-insulin or ${ }^{125} \mathrm{I}-\mathrm{HGH}$ was associated with:

(i) a heavy autoradiographic grain density over the choroid and tapetum ( $357 \pm 128$ grains $/ 10^{4} \mu \mathrm{m}^{2}$ of cut retinal surface: 16 experiments);

(ii) a light retinal grain density $\left(43 \pm 22\right.$ grains $/ 10^{4}$ $\mu \mathrm{m}^{2}$ of cut retinal surface: 16 experiments);

(iii) a light background grain density $(49 \pm 20$ grains $/ 10^{4} \mu \mathrm{m}^{2}: 16$ experiments);

(iv) autoradiographic grains in association with capillary walls.

The experiments in which the blood retinal barrier remained intact produced retinal grain densities that did not differ significantly from their background values. The mean control grain density in two experiments without ${ }^{125} \mathrm{I}$ hormone perfusion was $38 \pm 10$ grains per $\mu \mathrm{m}^{2}$ over all areas. However, it is of interest that in 2 experiments in which blood retinal barrier breakdown occurred (as shown by fluorescein leakage into the retina) the retinal grain density increased to choroidal levels.

These results suggest that while both ${ }^{125}$ I-insulin (approximate MW 6000) and ${ }^{125} \mathrm{I}-\mathrm{HGH}$ (approximate MW 21000) passed freely through the choriocapillaris fenestrae, neither hormone penetrated the blood retinal barrier in studies conducted with 15 minutes' perfusion with ${ }^{125} \mathrm{I}-\mathrm{HGH}$, and with periods of 10 to 60 minutes' perfusion with ${ }^{125}$ I-insulin.

\section{CAPILLARY WALL GRAINS: QUANTITATIVE} LIGHT MICROSCOPY BINDING

Both ${ }^{125} \mathrm{I}$-insulin and ${ }^{125} \mathrm{I}-\mathrm{HGH}$ perfusion resulted in the presence of autoradiographic grains lying over the interface between capillary cytoplasm and capillary lumen, suggesting binding to the capillary wall (see Fig. 4). By contrast, in the absence of perfusion with iodinated hormone the incidence of 'background' autoradiographic grains lying over this interface was very low $\left(0 \cdot 10\right.$ grain/100 $\mu \mathrm{m}^{2}$ capillary wall; 2 experiments, $n=10$ ).

To assess how specific this binding process was 10 different ${ }^{125}$ I-insulin and 4 different ${ }^{125}$ I-HGH experiments were performed with varying concentrations of labelled and unlabelled hormone for different perfusion periods, as summarised in Table 1. Retinal tissue was processed and a value for mean grain density obtained for each experiment. In all, over 3500 capillary profiles were individually measured and their grains counted.

In 3 different concentration/perfusion time 
Fig. 5 Contrasting effects of increasing concentrations of unlabelled hormone on ${ }^{125}$ I-insulin and ${ }^{125}$ I-HGH capillary wall grain density. Values are 'mean grain densities' \pm standard deviations (see text).

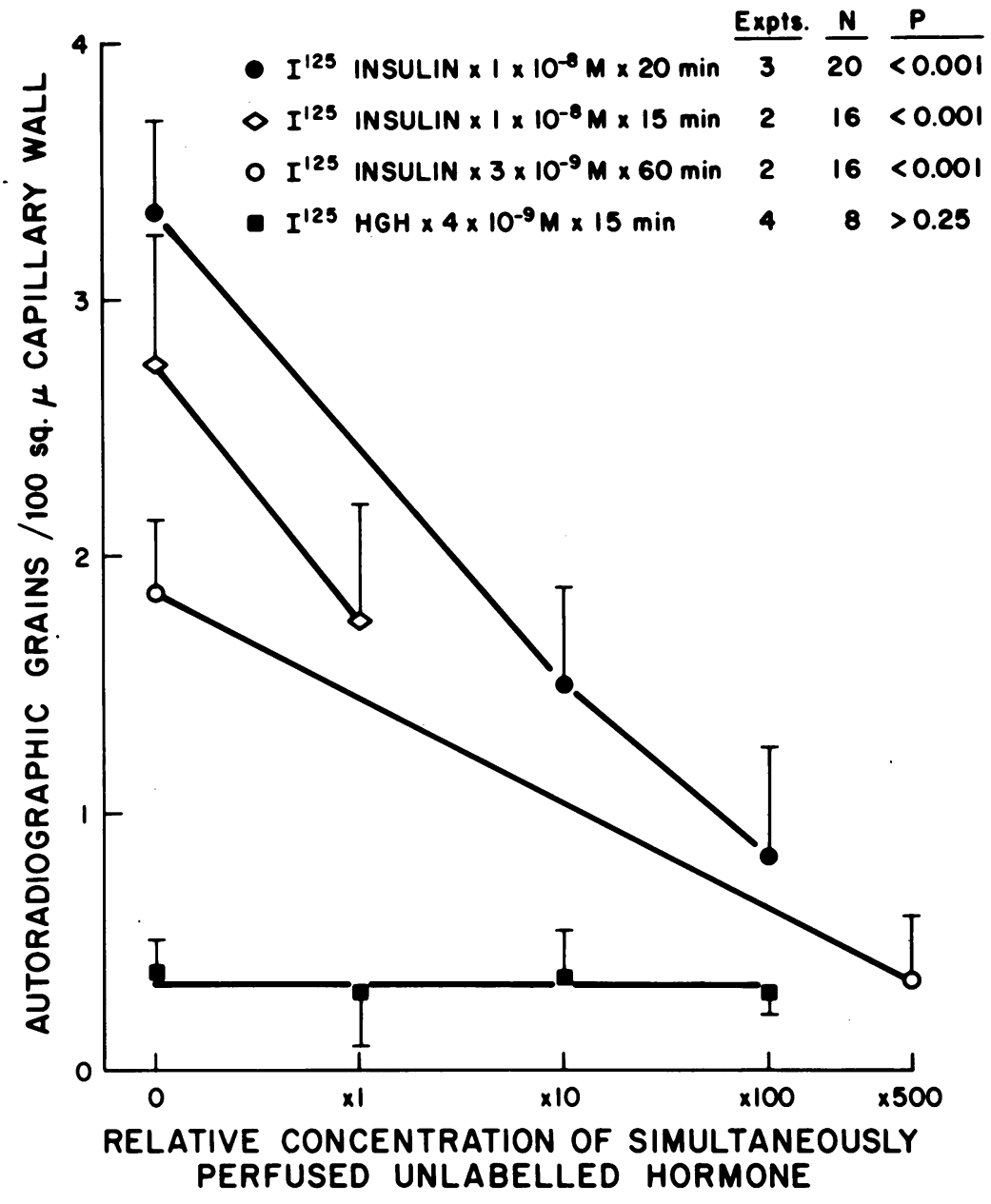

Table $1{ }^{125} \mathrm{I}$-insulin and ${ }^{125} \mathrm{I}-\mathrm{HGH}$ grain count data

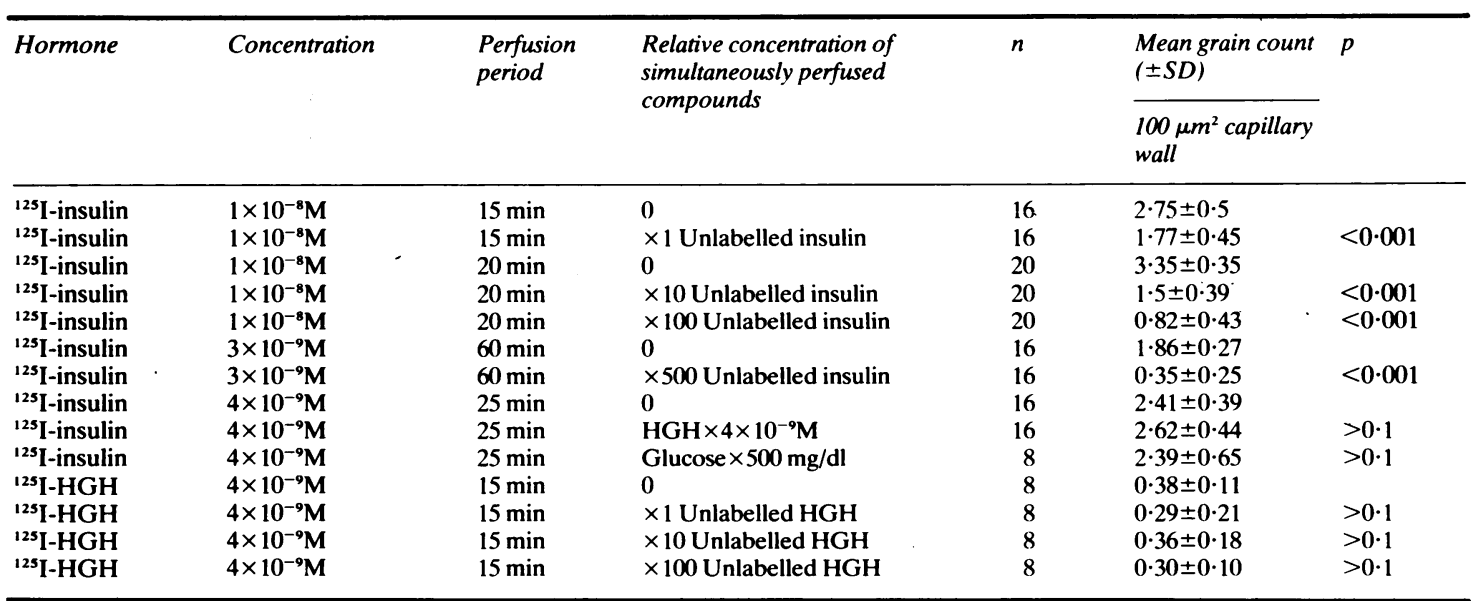

SI conversion: glucose $\mathrm{mg} / \mathrm{dl} \times 0.0555=\mathrm{mmol} / \mathrm{l}$. 


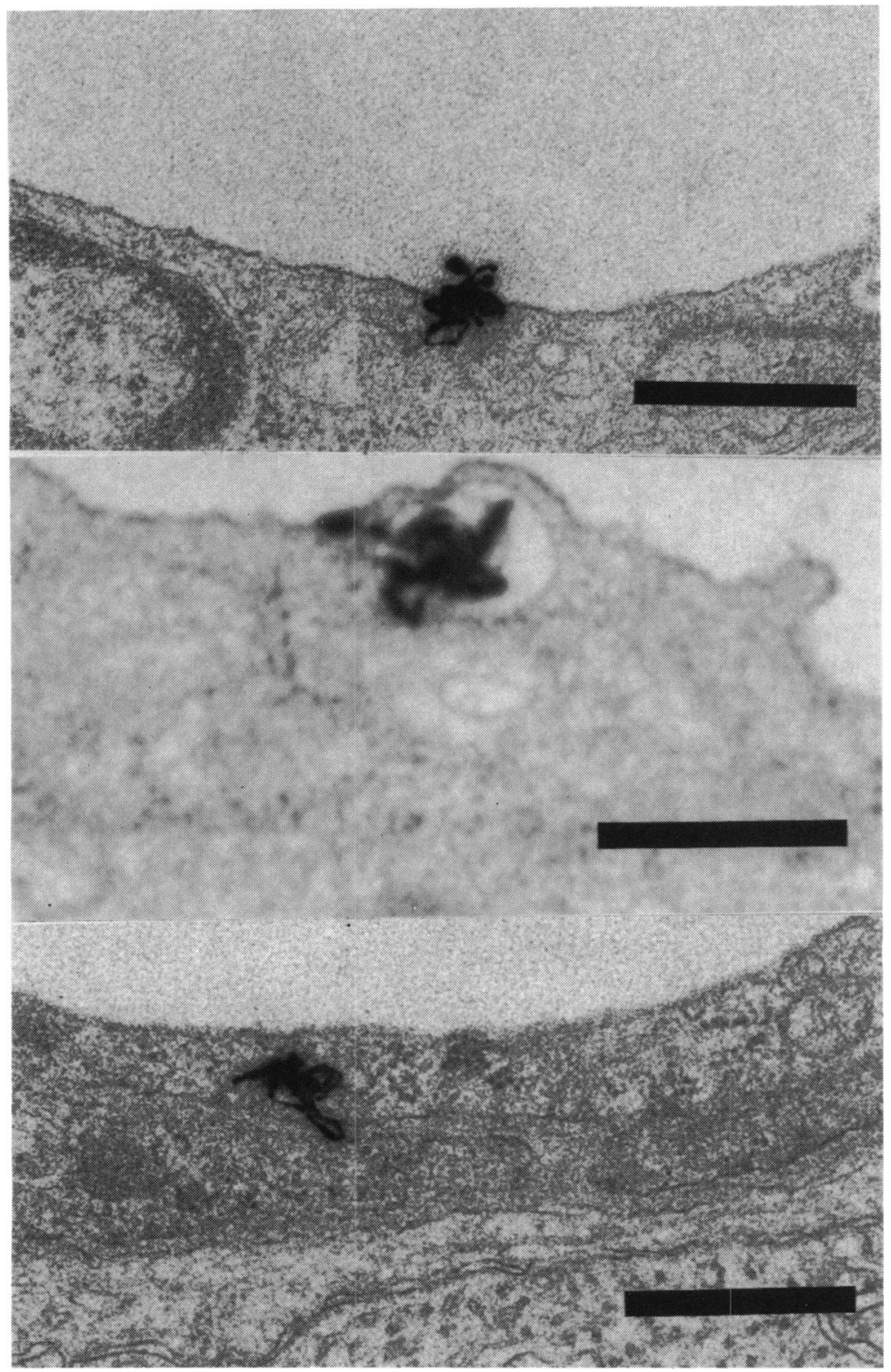

Fig. 6 Electron microscopic appearances of ${ }^{125}$ I-insulin autoradiographic grains. (Upper) cell wall associated. (Middle) Vesicle associated. (Lower) Cytoplasm associated. (Bars=0.5 $\mu \mathrm{m}$ ).

experiments involving 7 eyes ${ }^{125} \mathrm{I}$-insulin produced mean grain density values that were competitively reduced by increasing levels of unlabelled insulin (Fig. 5 and Table 1). Neither the presence of $\mathrm{HGH}$ nor a high glucose concentration significantly affected the ${ }^{125} \mathrm{I}$-insulin grain density. The value (of $0 \cdot 35 \pm 0 \cdot 25$ grains) obtained with a 500-fold excess of unlabelled insulin was taken to represent 'nonspecific binding' of ${ }^{125} \mathrm{I}$-insulin to the capillary wall. By contrast, ${ }^{125} \mathrm{I}-$ HGH produced low grain counts that did not vary with unlabelled HGH concentrations. In addition, the counts did not differ significantly either from each other or from the nonspecific binding value for ${ }^{125} \mathrm{I}$ insulin. It was concluded that ${ }^{125} \mathrm{I}$-insulin bound to specific binding sites on the endothelial cell wall, whereas HGH displayed only a low level of nonspecific binding.

ELECTRON MICROSCOPY AUTORADIOGRAPHY

By this technique 2 factors limited the yield of 
Fig. 7 Electron microscopic appearances of a retinal capillary with a pericyte and a pericyte associated autoradiographic grain (arrowed) after perfusion fixation (Bar=1 $\mu \mathrm{m})$.

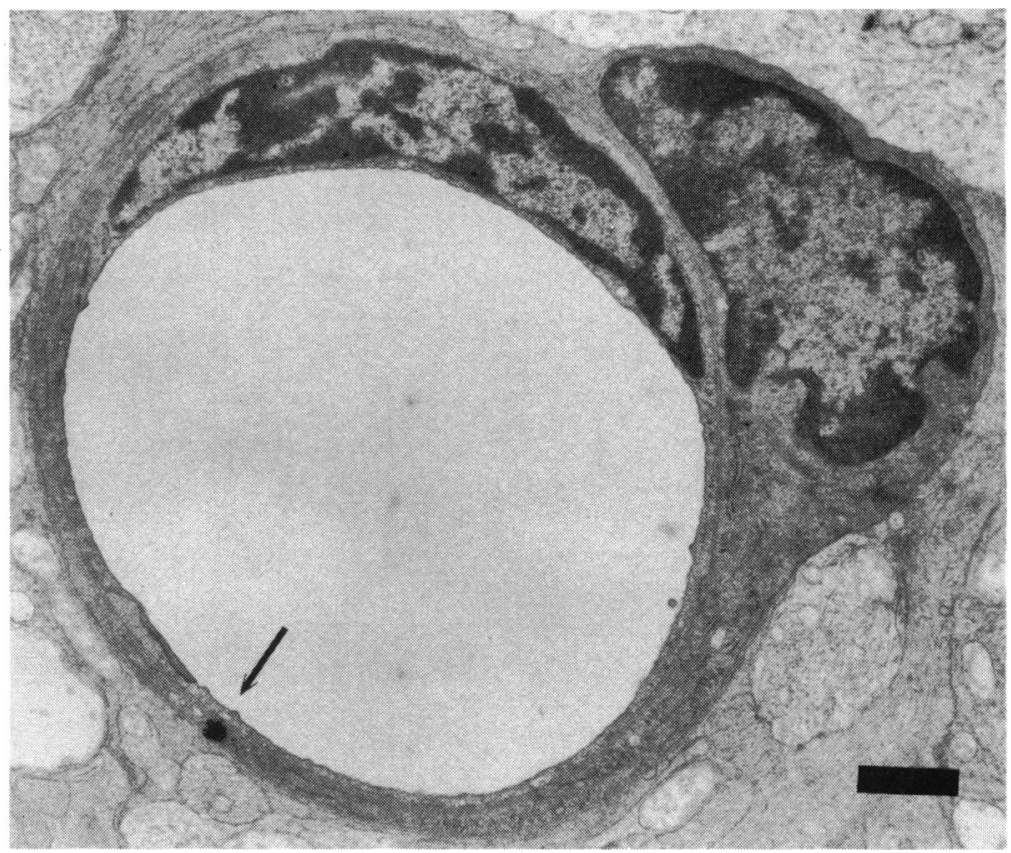

capillary wall associated autoradiographic grains at the electron microscopic (EM) level to levels where quantitative EM distribution analysis could not be attempted. ${ }^{19}{ }^{20}$ Firstly, the binding site concentration on the cell wall surface appears to be comparatively low. Secondly, the capillary profiles were separated by large areas of intervening retina, so that only a few profiles appeared on each grid. However, preliminary analysis of 116 capillary wall associated grains allowed the following observations to be made:

Capillary associated grains could be morphologically classified according to the structures over which they lay (Figs. 6, 7): (a) cell wall associated; (b) vesicle associated; $(c)$ cytoplasm associated; these ranged in distance as far as $850 \mathrm{~nm}$ from the cell wall.

With increasing periods of perfusion the distance from the cell wall to cytoplasm associated grains appeared to increase:

15 min perfusion: mean cell wall $\leftrightarrow$ grain centre distance $=89 \pm 99 \mathrm{~nm} ; \mathrm{n}=32 ; 3$ experiments.

$25+60$ min perfusion: mean cell wall $\leftrightarrow$ grain centre distance $=173 \pm 187 \mathrm{~nm} ; \mathrm{n}=34 ; 3$ experiments; $\mathrm{p}<0.025$ ).

Excess unlabelled insulin simultaneously perfused with the labelled insulin reduced not only the overall number of capillary wall associated grains in comparison with labelled insulin alone, but also the distance from the cell wall to the grain centre.

These preliminary observations suggest that ${ }^{125} \mathrm{I}-$ insulin may be internalised by retinal endothelial cells as it is in hepatocytes ${ }^{20}$ and fibroblasts, ${ }^{21}$ but a much larger EM study would be needed to establish this quantitatively.

\section{Discussion}

Distribution. Both ${ }^{125}$ I labelled hormones passed into the choroid, but neither hormone penetrated the retina. This would appear to be a reflection of their molecular size in relation to the known difference in permeability characteristics of the blood retinal barrier and the choriocapillaris, ${ }^{22}$ and is similar to findings with the blood brain barrier. ${ }^{2}$ Our findings that blood retinal barrier breakdown allows ${ }^{125}$ Iinsulin and ${ }^{125} \mathrm{I}-\mathrm{HGH}$ to penetrate the retina in large quantities makes it tempting to speculate on the possible role of these 2 potent growth factors ${ }^{1023}$ in the development of new vessels in diabetic retinopathy.

Binding. The binding data complement the previous report from this laboratory and suggest that there are specific binding sites on the luminal aspect of retinal capillaries, and that these sites are present in a relatively low surface concentration in comparison with traditional insulin target cells (e.g., hepatocytes). ${ }^{24}$

Our results are compatible with the binding site density found in rat brain microvessels in vivo ${ }^{2}$ found by similar autoradiographic technique. In that study Van Houten and Posner depicted a maximum value 
of 8 grains/'unit capillary' of luminal diameter 13-17 $\mu \mathrm{m}$ using $4 \mu \mathrm{m}$ thick sections, which corresponds to a value of 4 grains $/ 100 \mu \mathrm{m}^{2}$ when expressed in the same way as our results. By contrast, we did not find a regional difference in the eye, as reported in the brain, despite regional differences in ocular vessel diameter. In the perimacular region, for example, most of the capillary profile diameters lay in the range 4-7 $\mu \mathrm{m}$ compared with 6-14 $\mu \mathrm{m}$ in the equatorial region, yet the grain counts $/ 100 \mu \mathrm{m}^{2}$ from the 2 areas were similar in all the experiments.

Although not quantifiable in the present study, there was also noticeable grain concentration over the walls of retinal arterioles and venules as well as the choriocapillaris and retinal pigment epithelium, and, as with retinal capillaries, this concentration was reduced by simultaneously perfused unlabelled insulin. These observations, and reports of insulin binding to human umbilical arteries and veins, ${ }^{3}$ make it likely that retinal capillaries are not unique among ocular blood vessels in possessing insulin binding sites.

Binding to a specific binding site on the cell surface is the primary event in insulin action. ${ }^{24}$ Prior treatment of target cells with agents which remove or occupy insulin receptors renders the cells unresponsive to insulin in the surrounding medium. After binding has taken place it is usually possible to dissociate insulin from its receptors, particularly in studies carried out at low temperatures. ${ }^{24}$ However, at physiological temperatures another process, internalisation, may come into play. ${ }^{2021}$ This process involves the transport of the insulin molecule into the cell cytoplasm. Internalisation is not necessary for insulin action, as all the actions of insulin studied so far can take place after binding to the cell surface alone, even if internalisation is prevented. ${ }^{20}$ In hepatocytes internalisation appears to be followed by degradation of the molecule. ${ }^{20} \mathrm{By}$ contrast it has been suggested that insulin binding to vascular endothelium might be followed by transfer to subendothelial tissues. ${ }^{3}$

We found no evidence to suggest insulin transfer to the retina, but we did find grains lying over pericytes. Insulin binding sites have been found in pericytes ${ }^{6}$ in culture, and, for them to play a role in vivo, insulin must pass across the endothelium first. If this transport involves the vesicular pathway, then an effect on this pathway from diabetes, as has been found in capillaries elsewhere,${ }^{4}$ would lead to pericyte deprivation of insulin as well as other compounds. This would be relevant to the phenomenon of 'pericyte drop-out' in diabetic retinopathy. ${ }^{2526}$

What are these capillary insulin binding sites for? Capillary endothelial cells are responsible for maintaining the blood retinal barrier, as well as the manufacture of several products involved in thrombosis control such as prostacyclin ${ }^{27}$ and von Willebrand factor.

Diabetes is associated with widespread endothelial cell dysfunction, resulting in blood retinal barrier breakdown ${ }^{28}$ and eventual endothelial cell loss and capillary shutdown. ${ }^{25} 26$ If, as recent evidence for prostacyclin suggests, ${ }^{29}$ insulin is necessary for endothelial cell metabolism and the manufacture of endothelial cell products, then a reduction in available insulin, as in juvenile diabetes, or a reduction in receptor number, as found in many maturity onset diabetics, ${ }^{30}$ could harm both thrombosis control and endothelial cell maintenance of the blood retinal barrier.

We found no specific retinal capillary human growth hormone binding in our bovine eye preparation, in common with results in rat brain microvessels. ${ }^{2}$ This suggests that HGH's role in diabetic microangiopathy is mediated by an indirect mechanism.

In conclusion we have shown that ${ }^{125}$ I-insulin binds to specific sites present in relatively low concentrations on the luminal surface of retinal capillaries. Insulin does not penetrate the retina unless blood retinal barrier breakdown occurs. We have speculated on insulin's potential role in endothelial cell metabolism, and feel this merits further research.

The authors are grateful to Hans Stukenbrok for invaluable help with the autoradiography; Drs M. Sears, J. Hirsch, J. Stjernschantz, T. Sherk, and D. Gregerson, and Mr. B. Toftness for help and advice at various stages of this study.

This work was supported by NIH Grant No. EY 02905 and by a grant from the Eli Lilly Co., Indianapolis.

Dr C. James was the recipient of an MRC(UK) Alexander Pigott Wernher Memorial Trust travelling fellowship.

Materials. Bovine insulin was purchased from Sigma, St Louis. $\mathrm{HGH}+\mathrm{HGH}$ antibody were a gift from the National Pituitary Agency, Maryland. Iodine-125 was purchased from Amersham Corporation, Arlington heights, I1. Fresh blood and bovine eyes were obtained from Forte's Abattoir, N. Bradford. Antibovine insulin antibody was purchased from Miles-Yeda, Elkhart, Ind. 65101 .

\section{References}

1 Caird FI, Pirie A, Ramsell TG. Diabetes and the eye. Oxford: Blackwell, 1969: 62.

2 Van Houten M, Posner BI. Insulin binds to brain blood vessels in vivo. Nature 1979; 282: 623-5.

3 Bar RS, Peacock ML, Spanheimer RG, Veenstra R, Hoak JC. Differential binding of insulin to human arterial and venous endothelial cells in primary culture. Diabetes $1980 ; 29: 991-5$.

4 Osterby R, Gundersen HJ, Christensen NJ. The acute effect of insulin on capillary endothelial cells. Diabetes 1978; 27: 745-9.

5 Davidson C, Cotlier E. Invest Ophthalmol Visual Sci 1980; 19 (ARVO suppl): 167

6 Lucas SM, Parker D, Khilnani S, Frank R. Insulin receptors in cultured retinal pericytes. Diabetes 1980; 29: 101A. 
7 Passa P, Gauville C, Canivet J. Influence of musclar exercise on plasma level of growth hormone in diabetics with and without retinopathy. Lancet 1974; ii: 72-4.

8 Kohner EM, Dollery CT, Fraser TR, Bulpitt CJ. Effect of pituitary ablation on diabetic retinopathy studies by fluorescence angiography. Diabetes 1970; 19: 703-14.

9 Wright AD, Kohner EM, Oakley NW, Hartog M, Joplin GF, Russell-Fraser $T$. Serum growth hormone levels and the response of diabetic retinopathy to pituitary ablation. $\mathrm{Br}$ Med J 1969; ii: 346-8.

10 Ledet T. Growth hormone antiserum suppresses the growth effect of diabetic serum. Studies on rabbit aortic medial cell cultures. Diabetes 1977; 26: 798-803.

11 Leber T. Die Circulations-und Ernahrungsverhaltinisse des Auges. In: Graefe-Saemisch Handbuch. 2nd ed. Liepzig: Engelmann, 1903: part 2: 1 .

12 Smith P. On the eye of the ox and its internal blood vessels. Br J Ophthalmol 1921; 5: 385-402.

13 Seaman AJ, Rullman DR, Lutcher CL, Moffat C. The living extracorporeal eye. Scand J Clin Lab Invest 1965; 17 (suppl 84): 101-8.

14 Tazawa Y, Seaman AJ. The electroretinogram of the living extracorporeal bovine eye. The influence of anoxia and hypothermia. Invest Ophthalmol Visual Sci 1972; 11: 691-8.

15 Hunter WM, Greenwood FC. Preparation of iodine-131 labelled human growth hormone of high specific activity. Nature 1962; 194: 495-6.

16 Posner BI. Insulin receptors in human and animal placental tissue. Diabetes 1974; 3: 209-17.

17 Salpeter MM, Bachmann L. Electron microscope autoradiography. In: Hayatt MA, ed. Principles and techniques of electron microscopy: New York: Van Nostrand Reinhold, Biological applications. 1972: 2: 221-78.
18 Salpeter MM, Fertuck HC, Salpeter EE. Resolution in electron microscope autoradiography. III. Iodine-125, the effect of heavy metal staining and a reassessment of critical parameters. $J$ Cell Biol 1977; 72: 161-73.

19 Salpeter MM, Bachmann L, Salpeter EE. Resolution in electron microscope radioautography. J Cell Biol 1969; 41: 1-20.

20 Gordon P, Carpentier JL, Freychet O, Orci L. Internalisation of polypeptide hormones. Diabetologia 1980; 18: 263-74.

21 Maxfield FR, Schlessinger J, Shechter Y, Pastan I, Willingham MC. Collection of insulin, EGF and $\alpha 2$-macroglobulin in the same patches on the surface of cultured fibroblasts and common internalisation. Cell 1978; 14: 805-10.

22 Bill A. In: Moses RA, ed. Adler's physiology of the eye. 7th ed. St Louis: Mosby, 1981: chapter 6.

23 Petrides PE, Bohlen P. The mitogenic activity of insulin: an intrinsic property of the molecule. Biochem Biophys Res Commun 1980; 95: 1138-44.

$24 \mathrm{Kahn}$ CR. Membrane receptors for homrones and neurotransmitters. J Cell Biol 1976; 70: 261-86.

25 Ashton N. Studies of the retinal capillaries in relation to diabetic and other retinopathies. Br J Ophthalmol 1963; 47: 521-38.

26 Cogan DG, Toussaint D, Kuwabara T. Retinal vascular patterns. IV. Diabetic retinopathy. Arch Ophthalmol 1961; 66: 366-78.

27 Weksler BB, Marcus AJ, Jaffe EA. Synthesis of prostaglandin $1_{2}$ (Prostacyclin) by cultured human and bovine endothelial cells. Proc Natl Acad Sci USA 1977; 74: 3922-6.

28 Ashton $\mathrm{N}$. The blood retinal barrier and vaso-glial relationships in retinal disease. Trans Ophthalmol Soc UK 1965; 85: 199-229.

29 Harrison HE, Reece AH, Johnson M. Effect of insulin treatment on prostacyclin in experimental diabetes. Diabetologia 1980; 18: 65-8.

30 Olefsky JM. Insulin resistance and insulin action. An in vitro and in vivo perspective. Diabetes 1981 ; 30: 148-162. 